\title{
Two new species of Episymploce Bey-Bienko, 1950 (Blattodea, Ectobiidae, Blattellinae) from China
}

\author{
Ting-Ting Li', De-Xing Liu', De-Yi Qiu', Qiao-Yun Yue' \\ I Zhongshan Customs Technology Center, Zhongshan 528400, Guangdong, China \\ Corresponding author: Qiao-Yun Yue (779721036@qq.com)
}

Academic editor: Eliana Cancello | Received 2 January 2020 | Accepted 29 June 2020 | Published 29 July 2020

http://zoobank.org/5041585B-E93E-42B5-87FB-C1B067173A9D

Citation: Li T-T, Liu D-X, Qiu D-Y, Yue Q-Y (2020) Two new species of Episymploce Bey-Bienko, 1950 (Blattodea, Ectobiidae, Blattellinae) from China. ZooKeys 954: 31-46. https://doi.org/10.3897/zookeys.954.49738

\begin{abstract}
Two new species of Episymploce Bey-Bienko from China are described. Nine individuals of E. sichuanensis sp. nov. were collected from Sichuan Province and four individuals of E. maxima, sp. nov. were collected from Guangxi Province. Morphology, especially the wings, specialized abdominal tergum and genitalia of adults, are described and illustrated in detail. Episymploce sichuanensis sp. nov. is similar to E. kunmingi (Bey-Bienko, 1969), but can be easily distinguished by the reduced wings, bifurcated two processes at the hind margin of the supra-anal plate, and the unspecialized first abdominal tergum (T1). Episymploce maxima sp. nov. is similar to E. taiheizana Asahina, 1979 but is distinguished by its large size, the lateromedial margins of the subgenital plate without processes, and the unspecialized T1. A key to the recorded Episymploce species from China is provided in this paper.
\end{abstract}

\section{Keywords}

Blattaria, cockroaches, Dictyoptera, identification key, taxonomy

\section{Introduction}

The genus Episymploce was established by Bey-Bienko in 1950, with the type species E. paradoxura Bey-Bienko, 1950, who later described three other new species, E. marginata Bey-Bienko, 1957, E. popovi Bey-Bienko, 1957, and E. uncinata Bey-Bienko, 1969. Princis $(1969,1971)$ recorded six species of Episymploce, five of which originated from China. In 1979, Asahina (1979) redescribed the Japanese species E. amamiensis

Copyright Ting-Ting Li et al. This is an open access article distributed under the terms of the Creative Commons Attribution License (CC BY 4.0), which permits unrestricted use, distribution, and reproduction in any medium, provided the original author and source are credited. 
Asahina, 1977, reinterpreted the genus and described another two new species, $E$. princisi Asahina, 1979 and E. taiheizana Asahina, 1979. Asahina (1979) considered Ischnoptera multiramosa Karny, 1915, recorded by Karny and Shiraki, incompletely documented, while Princis (1969) pointed out a nomenclatural error and changed its name to E. karnyi Princis, 1969, but no detailed description was provided. Asahina (1979) renamed E. karnyi Princis, 1969 as E. princisi Asahina, 1979 and redescribed it. Roth (1985) then renamed E. princisi Asahina, 1979 to E. asahinai Roth, 1985 and redescribed the species again. Liu et al. (2017) also considered E. karnyi Princis, 1969 and I. multiramosa Karny, 1915 were synonyms of E. asahinai Roth, 1985. Phyllodromia formosana Shiraki, 1908 and I. yoshinoe Shiraki, 1931 from Taiwan were identified as subspecies of E. formosana (Shiraki, 1907) by Asahina (1979). Roth (1987d), Wang (2006) and Liu et al. (2017) considered E. formosana formosana (Shiraki, 1907) was a synonym of E. formosana (Shiraki, 1907).

Roth (1986) supplemented the genus and reclassified five species of Symploce as Episymploce. He considered that E. taiwanica (Bey-Bienko, 1969) was a synonym of E. sundaica (Hebard, 1929). Wang (2006) and Liu et al. (2017) agreed with Roth. Roth (1986) transferred six species of Symploce to Episymploce, and considered that E. castanea (Hanitsch, 1933) was a synonym of E. ussuensis Roth, 1985. Roth (1987a, 1987b, 1987c, 1987d) described 41 species of Episymploce from six countries, some being new records, of which 27 species and two subspecies were distributed in China, and a key to these Chinese species was provided.

Guo and Feng (1985) established Asymploce Guo \& Feng, 1985, and recorded two new species, Asymploce rubroverticis Guo \& Feng, 1985 and A. hunanensis Guo \& Feng, 1985 from China, but Roth (1991) subsequently revised this genus, placing it as a synonym of Episymploce, and placed these two species into Episymploce. Roth (1997) transferred 16 species of Symploce to Episymploce based on the supra-anal plate. In 2003, Roth (2003) transferred S. guizhouensis Feng \& Woo, 1988 and S. mamillatus Feng \& Woo, 1988 from Symploce to Episymploce. Wang at al. (2005) described a new species E. daozhenana Wang \& Feng, 2005 from Guizhou of China.

By now, there are more than 70 species of Episymploce recorded globally, of which 39 species are recorded in China (Beccaloni 2014); a key of the published 39 species and the two new species reported here is provided in this paper.

\section{Materials and methods}

On 6 April and 3 May 2014, the second author and another colleague collected specimens in Daheishan, Panzhihua County, Sichuan Province, and Nonggang Village, Longzhou County, Chongzuo City, Guangxi Province. The specimens were brought back to the laboratory for freezing, flattening of wings and limbs with parchment paper, pinning with needles, and drying for preservation. The tergum behind the seventh abdominal tergum (T7) of the male specimen was cut off, placed into a $1.5 \mathrm{ml}$ centrifuge tube with $10 \% \mathrm{NaOH}$ and digested at $70{ }^{\circ} \mathrm{C}$ for $30-45 \mathrm{~min}$. After the digestion, $\mathrm{NaOH}$ was removed from the centrifuge tube, and the specimen was rinsed thrice 
with water before examination. The specimens were dissected and observed under a ZEISS Discovery V12 stereo microscope. Photographs were taken with a ZEISS/Smart Zoom 5 and Canon EOS 5D Mark III, and illustrated with Adobe Photoshop CC 2017 software. After illustration, the genitalia were stored in $0.5 \mathrm{ml}$ centrifuge tubes containing 50\% glycerol. The type specimens were deposited in Zhongshan Customs Technology Center.

The terminology used in this paper follows Roth $(1977,1979,2003)$.

\section{Taxonomy}

\section{Episymploce Bey-Bienko, 1950: 157.}

Type species. Episymploce paradoxura Bey-Bienko, 1950: 157.

Diagnosis. According to the traits proposed by Bey-Bienko (1950), Asahina (1979) and Roth (1986), this genus can be described as follows: the tegmina and wings are fully developed. Wings cubitus anterior vein has 1-5 complete and 1-6 incomplete branches, and the triangular apical area is small, reduced or absent. The first abdominal tergum can be specialized or unspecialized; the seventh abdominal tergum is always specialized; right and left lateral plates of the ninth abdominal tergum are similar, or the size and shape are obviously different, and the apex can be with or without small spines. The supra-anal plate is asymmetrical, symmetrical, or approximately symmetrical, the apex of the posterior margin is invaginated, or slightly concave; the subgenital plate is asymmetrical. The anteroventral margin of the front femora is of Type A3, rarely Type B, or between Type A and Type B. The male left aedeagus is in the shape of a hook.

Distribution. China; Indonesia (Sumatra, Sulawesi, Java, Flores); Japan; India; Laos; Vietnam; Philippines; Thailand; Borneo Island; Nepal; Burma; Malaysia; Singapore; Australia; Papua New Guinea.

Remarks. We agree with Roth (1987d), Wang (2006) and Liu et al. (2017) that E. taiwanica (Bey-Bienko, 1969) is a synonym of E. sundaica (Hebard, 1929), and agree with Roth (1987d) and Liu et al. (2017) that E. karnyi Princis, 1969 is a synonym of $E$. asahinai Roth, 1985. We also agree with Asahina (1979), Roth (1987d), Wang (2006) and Liu et al. (2017) that E. formosana formosana (Shiraki, 1907) is a synonym of E. formosana (Shiraki, 1907). So, E. taiwanica (Bey-Bienko, 1969), E. formosana formosana (Shiraki, 1907) and E. karnyi Princis, 1969 were not be included in the key below. Fortyone species in Episymploce, including all published 36 species, three subspecies and two newly described species are included in this key, which is adapted from Roth (1987d).

\section{Key to species of Episymploce from China (males)}

1 Anteroventral margin of front femur Type A3, rarely intermediate between

Type $A$ and B.......................................................................... 2

- $\quad$ Anteroventral margin of front femur Type B3 ....................................8 
Hind margin of supra-anal plate shallowly concave in middle and without papilla mesad....

Hind margin of supra-anal plate shallowly concave on the apex and with a minute papilla mesad.

E. asabinai Roth, 1985

Subgenital plate asymmetrical, styles simple, left and right lateromedial margins with spine-like processes. Left and right lateral plateral of T9 almost same length, ventral margins of both plates with 3 spines near apex.

E. taibeizana Asahina, 1979

Subgenital plate asymmetrical, styles simple, left and right lateromedial margins without processes. Left and right plate plateral of T9 similar, ventral margins of both plates without spines E. maxima sp. nov. Supra-anal plate divided. Supra-anal plate undivided, ligulate E. ligulata Bey-Bienko, 1957 Hind margin of subgenital plate with a U-or V-shaped excavation Hind margin of subgenital plate without a U-or V-shaped excavation........11 Left lobe of supra-anal plate wider than right lobe, inner margin of supra-anal plate with a curved incision, inner margin apex with a small papilla

\section{E. mamillatus (Feng \& Woo, 1988)}

Left lobe of supra-anal plate wider than right lobe, inner margin apex of supra-anal plate without papilla

Left and right lateral plateral of T9 almost same length, posteroventral margins without spines

E. sundaica (Hebard, 1929)

Left and right lateral plateral of T9 not similar, posteroventral margins with spines.

Basolateral of subgenital plate without spine-like process, right inner ventral margins with a strong spine E. cheni (Bey-Bienko, 1957) Basolateral of subgenital plate each with a spine-like processes..... Left thickened margin of subgenital plate produced transversely truncated, right style long and straight covered with dense hairs

E. subvicina (Bey-Bienko, 1969)

Left thickened margin of subgenital plate produced cylindrical, right style long and straight not covered with dense hairs

E. vicina (Bey-Bienko, 1954)

11 Left and right processes crossed of supra-anal plate hind margin ...............12

Left and right processes uncrossed of supra-anal plate hind margin............14

12 Left and right ventral margins of T9 without serrations ..........................13 Left ventral margins with tines, right ventral margins with or without serrations

E. Princisi (Bey-Bienko, 1969)

13 Left and right lateral plates of T9 with spines on ventral margin

.E. malaisei (Princis, 1950)

- Left lateral plate of T9 without spines on posteroventral margin, right lateral plate with or without spines. 
14 Ventral margins of T9 with a long spine. Hind margin apex of subgenital plate with a digitiform process

E. malaisei externa (Bey-Bienko, 1969)

Ventral margins of T9 without spine. Hind margin apex of subgenital plate without process

E. malaisei malaisei (Princis, 1950)

15 Left and right lobes of supra-anal plate with equal width, right apex spinelike, left one round E. dimorpha (Bey-Bienko, 1958)

Left and right lobes of supra-anal plate not equal width.

16 Left and right processes of supra-anal plate joined

Left and right processes of supra-anal plate separate Hind margin of both lateral plates of T9 transversely truncated, ventral margins projecting posteriorly with spine-like processes or without processes.. 18 Hind margin of left lateral plate of T9 obliquely truncated, posteroventral angles of right plate with slight processes ..... E. quarta (Bey-Bienko, 1969) Left thickened hind margin of subgenital plate spicular, right margin with an upright or curved hooklike style.

Left thickened hind margin of subgenital plate strongly spinulose, right margin without upright style....

E. secunda (Bey-Bienko, 1957) Right margin of subgenital plate with a large and upright style

E. prima (Bey-Bienko, 1957)

Right margin of subgenital plate with a large and curved hooklike style....

E. tertia (Bey-Bienko, 1957)

20 Left and right processes of supra-anal plate curved to the same side of ventral margin

Left and right processes of supra-anal plate curved to different sides of ventral margin

Middle with fleshy elevation of T7 with a pair of fossae on each side

Middle without fleshy elevation of T7 with depressions on each side....

E. unicolor (Bey-Bienko, 1958)

Hind margin of supra-anal plate process on the middle part, chelate. Pronotum with black brown blotch

E. tridens (Bey-Bienko, 1957)

Hind margin of supra-anal plate crevice on the middle part, apex of both lobe with curved long spine-like processes, directed along hind margin. Pronotum front margin and disk black brown, lateral and hind margin yellowishbrown

E. hunanensis (Guo \& Feng, 1985)

23 Right plate of subgenital plate with an irregular lamellar formation

\section{E. zagulajevi (Bey-Bienko, 1969)}

Right plate of subgenital plate without an irregular lamellar formation.....24

25 Hind margin of apex of supra-anal plate with two processes without bifurcate spine. E. kryzhanovskii (Bey-Bienko, 1957)

- $\quad$ Hind margin of apex of supra-anal plate with two processes with bifurcate spine 
Hind margin apex of supra-anal plate with two bifurcate processes.....

\section{E. sichuanensis sp. nov.}

- $\quad$ Hind margin of supra-anal plate with right process bifurcate, left process spine-like E. kunmingi (Bey-Bienko, 1969)

27 Left and right lateral plates of T7 with a small fossea. Right lobe of apex of supra-anal plate spine-like, left lobe broadly with an adpressed transverse spine ventrally near apex

E. spinosa (Bey-Bienko, 1969)

Left and right lateral plates of T7 with a depression. Left and right lobes of supra-anal plate spine-like, left lobe with a long spine ventrally near apex....

E. longiloba (Bey-Bienko, 1969)

Supra-anal plate divided in two.

29 Middle of T7 with two fossea covered in hairs

E. marginata Bey-Bienko, 1957

Middle of T7 with a pair broad fossea without hair covering.

30 Supra-anal plate semitubular, left margin apex with a long style, right margin near apex with a long style, basolateral with a process

E. popovi Bey-Bienko, 1957

Supra-anal plate weakly asymmetrical, triangular, left margin apex with two long styles, left and right basolateral without processes......

E. forficula (Bey-Bienko, 1957)

31 Hind margin of subgenital plate with V-shaped excavation

Hind margin of subgenital plate without V-shaped excavation

32 Right lobe ventrally of supra-anal plate with an adpressed transverse spine... E. daozhenana Wang \& Feng, 2005

- $\quad$ Right and left lobe of supra-anal plate without spines

33 Left and right lateral plates of T7 with a small fossea..................................34

Left and right lateral plates of $\mathrm{T} 7$ without fossea.

34 Left and right lateral plates basolateral of subgenital plate without processes, left plate terminating with a small spine, two styles long spine-like

E. paradoxura Bey-Bienko, 1950

Left and right lateral plates basolateral of subgenital plate with processes, left plate process is 2.5 times longer than the right plate process, left style curved hooks directed across left side of plate, right style straight spine-like obliquely directed across supra-anal plate

E. potanini (Bey-Bienko, 1950)

Left and right lateral plates basolateral of subgenital plate with process, left plate thickened, terminating with a small spine, styles dissimilar, their bases widely separated.

E. hassenzana Roth, 1987

- $\quad$ Left and right lateral plates basolateral of subgenital plate with processes, left plate thickened, terminating without a small spine, both styles nearly touch- 
ing basally, left style long spine-like, right style directed across right rear.......

E. paravicina (Bey-Bienko, 1969)

36 Left and right ventral margins of apex of T9 with spines...........................37

- $\quad$ Left and right ventral margins of T9 directed to long spine-like processes....39

37 Hind margin near left corner of supra-anal plate with a larger deflexed spinelike process, left margin apex thickened, hind margin medially with a pair of minute filamentous processes

E. splendens (Bey-Bienko, 1957)

- $\quad$ Hind margin of supra-anal plate each terminating with a spine-like deflexed process, left margin apex not thickened, hind margin medially without filamentous processes

38 Right and left lateral plates of T9 similar, hind margin transversely truncated, each with ventral margin terminating in a small spine

.E. formosana (Shiraki, 1907)

- $\quad$ Left ventral margin of T9 with a small spine, right ventral margin without spine......

E. formosana yoshinoe (Shiraki, 1931)

39 Upper base of both sides of supra-anal plate black brown. A red inverted pentagram marking is formed on vertex, ocular and antennal areas.

E. rubroverticis (Guo \& Feng, 1985)

- $\quad$ Upper base of both sides of supra-anal plate not black brown. No red inverted pentagram marking present on the face.

40 Left lateral plate of T9 with a narrow, apex spine-like, right plate short with a long, curved spine, not inserted in genital cavity. Pronotum with a pair of rust-chestnut spots.

E. uncinata Bey-Bienko, 1969

- $\quad$ Left lateral plate of T9 with a short spine-like, right plate with a long spine, inserted in genital cavity. Pronotum yellowish-brown

E. guizhouensis (Feng \& Woo, 1988)

\section{Episymploce sichuanensis sp. nov.}

http://zoobank.org/290ECF9F-4DA0-4EEF-9086-4AB258357B65

Figures 1-14

Specimens examined. Holotype: 1 male, $26^{\circ} 38.48^{\prime} \mathrm{N}, 101^{\circ} 41.62^{\prime} \mathrm{E}$, Daheishan, Panzhihua City, Sichuan Province, 6 April 2 014, coll. Ke-Liang Wu et De-Xing Liu. Allotype: 1 female, paratype: 7 males, allotype and paratype were collected together with holotype.

Diagnosis. This species is similar to E. kunmingi (Bey-Bienko, 1969), but can be distinguished as follows: 1) tegmina and wings reduced, only reaching the second abdominal tergum (T2), while in E. kunmingi (Bey-Bienko, 1969) tegmina and wings reach the apex of abdomen; 2) T1 is unspecialized, whereas T1 is specialized in $E$. kunmingi (Bey-Bienko, 1969); 3) two inwardly curved bifurcate processes on the hind margin of the supra-anal plate, while in E. kunmingi (Bey-Bienko, 1969) right process bifurcate and left process spine-like. 


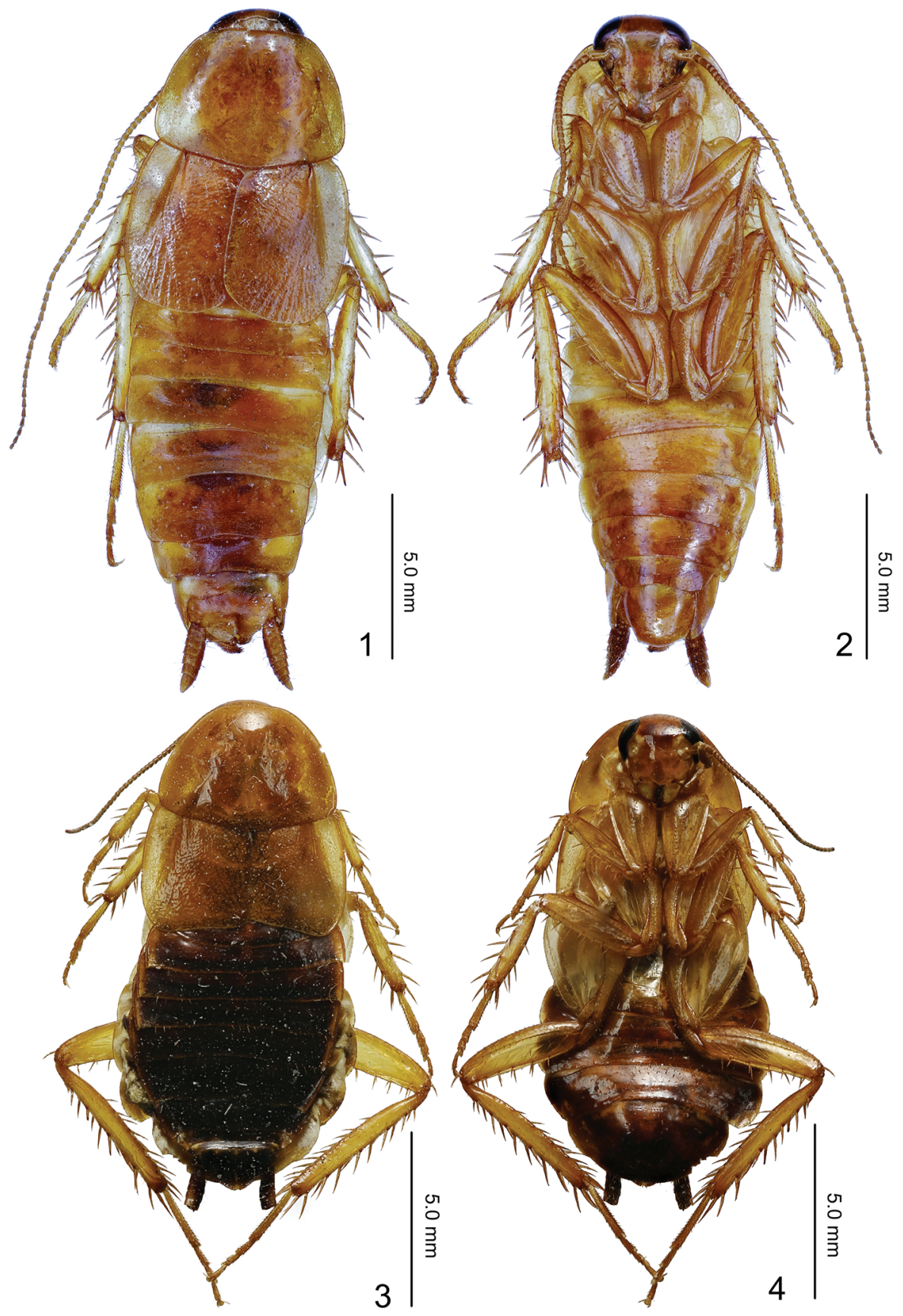

Figures I-4. Episymploce sichuanensis sp. nov. I male, dorsal view $\mathbf{2}$ male, ventral view $\mathbf{3}$ female, dorsal view 4 female, ventral view. 


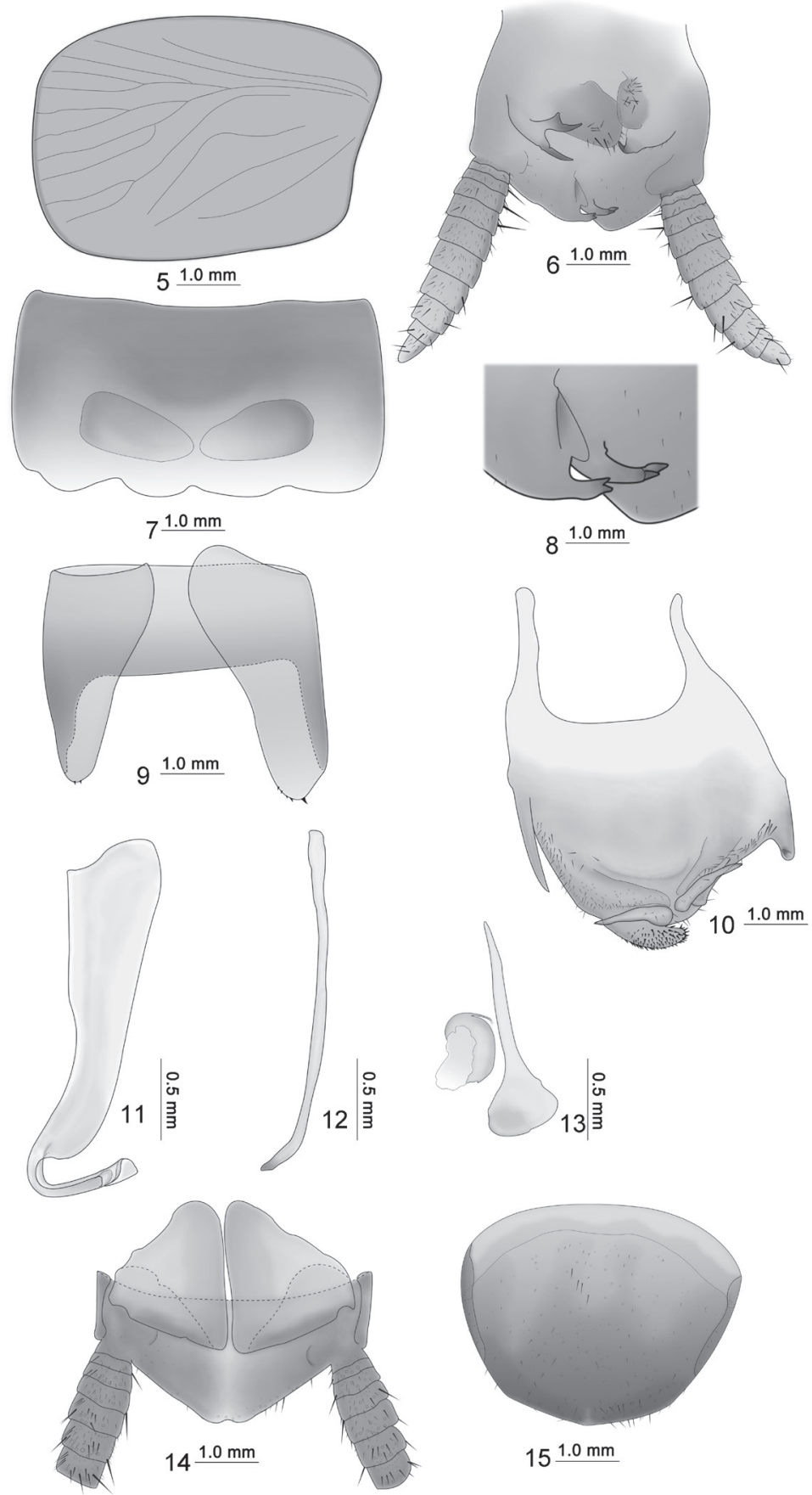

Figures 5-I5. Episymploce sichuanensis sp. nov. 5 tegmen $\mathbf{6}$ male, supra-anal plate and paraprocts, ventral view 7 male, T7, dorsal view 8 male, bifurcate process of the supra-anal plate $\mathbf{9}$ male, T9, ventral view $\mathbf{1 0}$ male, subgenital plate, dorsal view II male, left aedeagus $\mathbf{2}$ male, median aedeagus $\mathbf{3}$ male, right aedeagus $\mathbf{I} \mathbf{4}$ female, supra-anal plate and paraprocts, ventral view $\mathbf{5}$ female, subgenital plate, ventral view. 
Description. Male, pronotum: length $\times$ width: $2.8-3.0 \times 3.8-4.4 \mathrm{~mm}$; tegmen: $3.5-4.0 \mathrm{~mm}$; overall length (including tegmen): $16.2-17.9 \mathrm{~mm}$. Female, pronotum: length $\times$ width: $3.2 \times 5.0 \mathrm{~mm}$; tegmen: $3.8 \mathrm{~mm}$; overall length (including tegmen): $14.4 \mathrm{~mm}$.

Small size. Body yellowish orange, head extending somewhat beyond pronotum, ocellus white, interocular space almost equivalent to ocellus space. Pronotum approximate ladder-like, hind margin wide. Tegmina and wings reduced, veins inconspicuous, reaching of T2. Anteroventral margin of front femur Type A3; the first tarsus of the hind leg longer than the sum of the remaining tarsi; tarsal claws symmetrical and unspecialized, arolium and pulvillus present. The T1 unspecialized; T7 specialized with a pair of approximately triangular depressions (Fig. 7); T9 asymmetrical with left side longer than right, apex margin with some small spines (Fig. 9). Male supra-anal plate asymmetrical, hind margin of lamina bilobed, left hind margin has two inwardly curved processes, apex process of which is bifurcate (Figs 6, 8); left side paraproct with three processes and right side with single process. Subgenital plate asymmetrical, basolateral with two processes, left process longer, and apex of right process curved; left of hind margin apparently thicker and covered strongly spinulose, middle hind margin with two spine-like processes reversed and outwardly with long styles (Fig. 10); left aedeagus hook-shaped (Fig. 11). Female is similar to male; abdominal tergum suffused with dark brown, supra-anal plate symmetrical, approximately triangular, apex concave (Fig. 14). Subgenital plate simple and hind margin rounded (Fig. 15).

Etymology. Species name sichuanensis refers to the type locality.

Distribution. China (Sichuan).

\section{Episymploce maxima sp. nov.}

http://zoobank.org/4C780B62-095A-48CD-9765-C7BD7EEAA95C

Figures 16-30

Specimens examined. Holotype: 1 male, $22^{\circ} 28.26^{\prime} \mathrm{N}, 106^{\circ} 57.43^{\prime} \mathrm{E}$, Nonggang Village, Longzhou County, Chongzuo City, Guangxi Province, 3 May 2014, coll. Ke-Liang Wu et De-Xing Liu. Allotype: 1 female, paratype: 1 male, 1 female, all speciemens were collected at the same place at the same time.

Diagnosis. This species is similar to E. taiheizana Asahina, 1979, but can be distinguished as follows: 1) lateromedial margins of subgenital plate without processes, while with processes in E. taiheizana Asahina, 1979; 2) T1 was unspecialized, but T1 was specialized in E. taiheizana Asahina, 1979; 3) ventral margins of T9 without spines, but with 3 spines in E. taiheizana Asahina, 1979.

Description. Male, pronotum: length $\times$ width: $5.2-6.0 \times 6.0-6.5 \mathrm{~mm}$; tegmen: $23.5 \mathrm{~mm}$; overall length (including tegmen): $27.8-28.5 \mathrm{~mm}$. Female, pronotum: length $\times$ width: $5.5-6.6 \times 6.0-6.6 \mathrm{~mm}$; tegmen: $23.4 \mathrm{~mm}$; overall length (including tegmen): $27.8-29.5 \mathrm{~mm}$. 

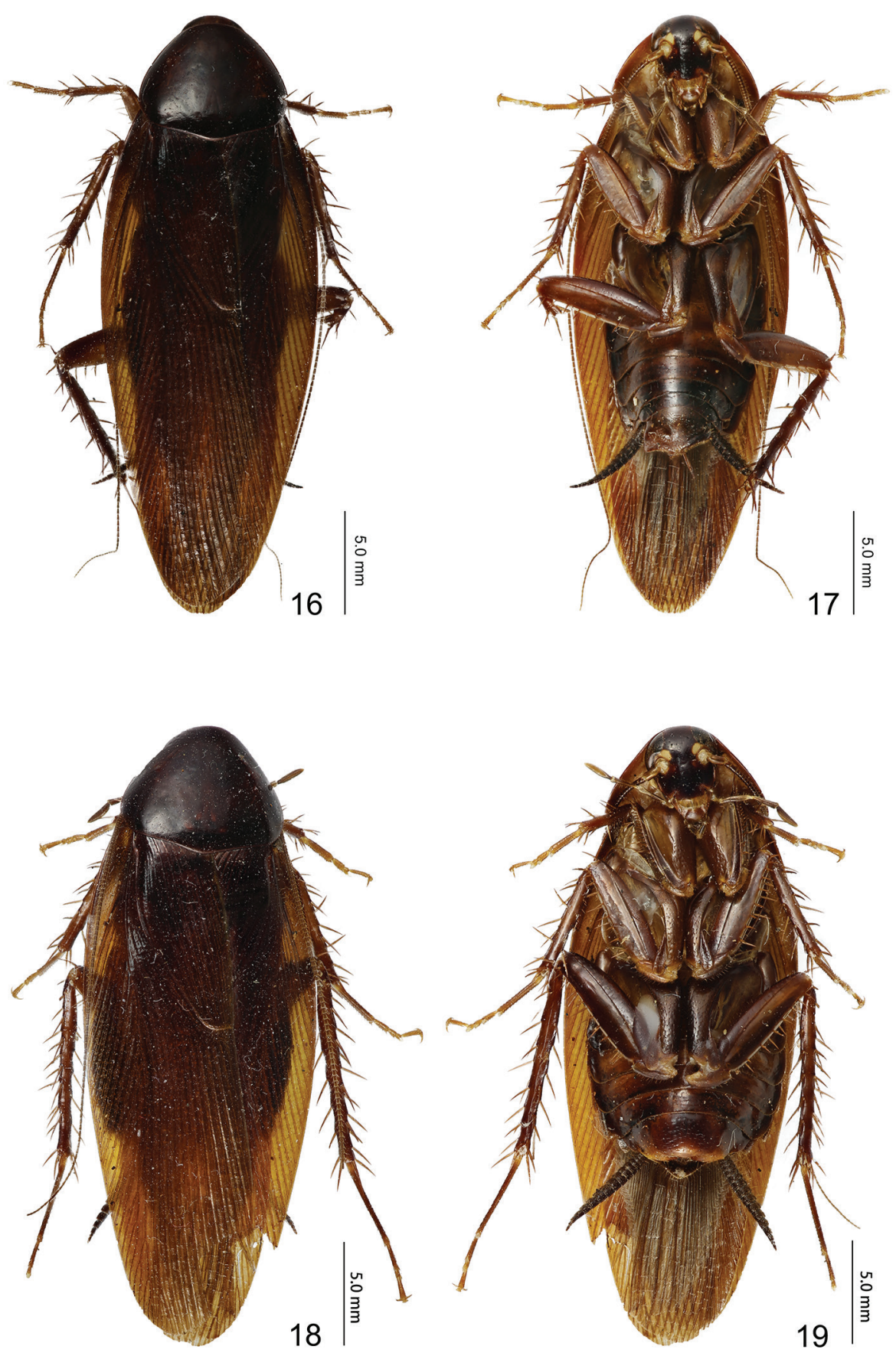

Figures 16-19. Episymploce maxima sp. nov. 16 male, dorsal view 17 male, ventral view $\mathbf{1 8}$ female, dorsal view 19 female, ventral view. 

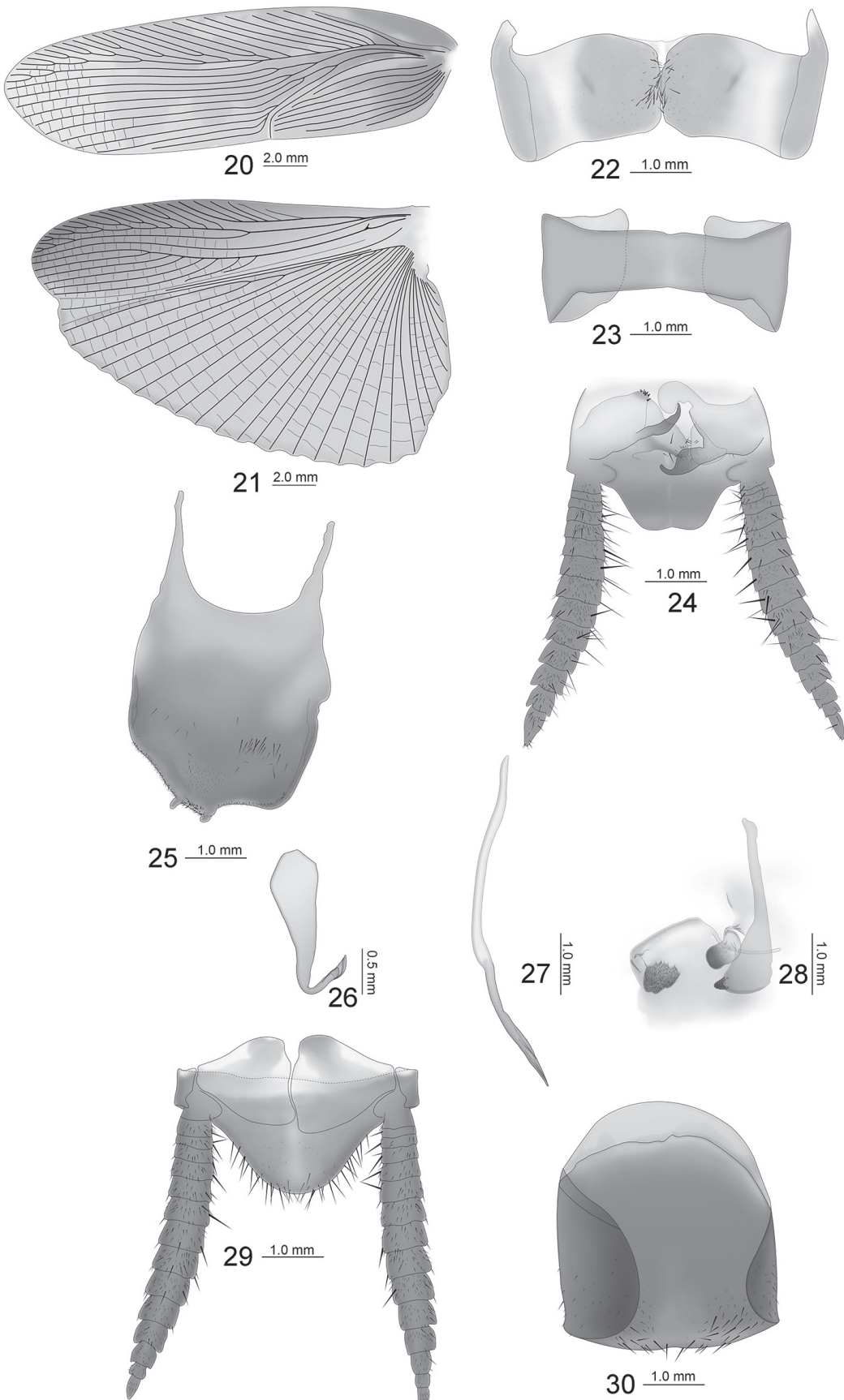

Figures 20-30. Episymploce maxima, sp. nov. 20 tegmen $\mathbf{2 1}$ hind wing 22 male, T7, dorsal view $\mathbf{2 3}$ male, T9, dorsal view $\mathbf{2 4}$ male, supra-anal plate and paraprocts, ventral view $\mathbf{2 5}$ male, subgenital plate, dorsal view $\mathbf{2 6}$ male, left aedeagus $\mathbf{2 7}$ median aedeagus $\mathbf{2 8}$ male, right aedeagus $\mathbf{2 9}$ female, supra-anal plate and paraprocts, ventral view $\mathbf{3 0}$ female, subgenital plate, ventral view. 
Large size. Body dark brown, head extending beyond the pronotum, vertex tawny, ocellus yellow, face dark brown, interocular space is $3 / 4$ of ocellus space, antenna base dark brown, a pair of symmetrical reddish-brown dots next to the antenna sockets, antenna sockets slightly wider than ocellus width. Pronotum approximate triangular, hind margin wide, dark brown. Tegmina and wings fully developed, tegmina extending beyond the end of abdomen; hind wing with radius vein branched near middle; medial vein simple; cubitus anterior vein with five complete and two incomplete branches, triangular apical area small. Anteroventral margin of front femur Type A3; the first tarsus of the hind leg longer than the sum of the rest tarsi; tarsal claws symmetrical and unspecialized, arolium and pulvillus present. The T1 unspecialized; T7 specialized with numerous hairs in the intermediate region (Fig. 22); right and left lateral plates of the T9 are similar, hind margins truncate, posterior corners rounder (Fig. 23). Male supra-anal plate symmetrical, middle of the hind margin concave (Fig. 24); subgenital plate asymmetrical, two styles on the left side of the hind margin, with some spines in the interstylar margin (Fig. 25); left aedeagus hook-shaped (Fig. 26); median aedeagus exposed, extending beyond the supra-anal plate, spicular (Fig. 27). Female similar to male; supra-anal plate and subgenital plate symmetrical, hind margin round, apex with small concavity (Figs 29, 30).

Etymology. Species name maxima refers to its large size, currently the largest species in Episymploce.

Distribution. China (Guangxi).

\section{Discussion}

The genus Symploce was established before the genus Episymploce, but it turned out that many species from other genera of cockroaches were included (Roth 1984). In 1950, Bey-Bienko (1950) established the genus Episymploce, and pointed out the difference between Episymploce and Symploce in the hind wings, the irregularly branched radial of the tegmina, and the conversion of the hind lateral processes of the T9 into spines. Subsequently, Asahina (1979) redefined Episymploce and dissected the male genitalia in detail, providing more reliable features for distinguishing Symploce from Episymploce. Roth (1986) considered that Bey-Bienko put too much emphasis on wing venation when distinguishing Episymploce from Symploce. He considered that the wing venation could not be used to distinguish Episymploce from Symploce, and suggested the symmetry of the supra-anal plate should be considered. He transferred E. marginata Bey-Bienko, 1957, E. popovi Bey-Bienko, 1957 and E. ligulata Bey-Bienko, 1957 to Symploce. In 1984 and 1986, Roth $(1984,1986)$ respectively collated and supplemented the characteristics of the abdominal tergum, wing venation, anteroventral margin of front femur, and supra-anal plate to distinguish Symploce from Episymploce. More specializations of the male abdominal tergum were observed in Symploce than in Episymploce. In 1997, Roth rejected that symmetry of the supra-anal plate distinguished between Episymploce and Symploce, and returned E. marginata Bey-Bienko, 1957, E. popovi 
Bey-Bienko, 1957 and E. ligulata Bey-Bienko, 1957 to Episymploce. We do not think it is appropriate to distinguish one genus from another only by a single feature as there are many similarities between the characteristics of Episymploce and Symploce.

In 1985, Roth (1985) compared the characteristics of Blattella, Symploce, Parasymploce and Episymploce. He considered that the difference between Parasymploce and the other three is that the supra-anal plate is symmetrical and the T7 was always specialized. Roth (1995) considered Aristiger and Parasymploce were synonyms of Hemithyrsocera. The supra-anal plate of E. sichuanensis sp. nov. is asymmetrical, which is obviously different from Hemithyrsocera. Episymploce maxima sp. nov. has similar features to Hemithyrsocera on the supra-anal plate and T7, but E. maxima sp. nov. has 5 complete and 2 incomplete branches in the cubitus anterior vein of the hind wing, while the cubitus anterior vein of the hind wings of Hemithyrsocera have no branches or 1-3 complete branches, and no incomplete branches. The supra-anal plate of E. sichuanensis sp. nov. is asymmetrical and T1 unspecialized, T7 and T9 are specialized. In the diagnosis of Symploce (Roth, 1984), the supra-anal plate was described as symmetrical, rarely asymmetrical, and T7 and T9 without specialization at the same time. Episymploce maxima sp. nov. was similar to the genus Symploce in regard to the supra-anal plate, but the subgenital plate of Symploce has a highly specialized style, while the subgenital plate of $E$. maxima sp. nov. has a simple style and T1 is unspecialized, T7 specialized, and the left and right plate of T9 are similar. We think that these two new species do not agree with the characteristics of Symploce and Hemithyrsocera, whereas they do agree with the characteristics of the genus Episymploce.

\section{Acknowledgements}

We thank Mr Ke-Liang Wu for efforts in collecting the valuable specimens. We also cordially thank Dr Xian-Wei Liu (Chinese Academy of Sciences) for his kind assistance in the identification of the specimens. This project was funded by the National Key R\&D Program of China (2016YFF0203200) and Zhongshan City Funded Project (Grant no. 2018B1022).

\section{References}

Asahina S (1979) Taxonomic notes on Japanese Blattaria. XII. the species of the tribe Ischnopterites, II (ind. Taiwanese species). Japanese Journal Sanitary Zoology 30(4): 335-353. https://doi.org/10.7601/mez.30.335

Beccaloni G (2014) Cockroach Species File Online. Version 5.0/5.0. https://Cockroach.SpeciesFile.org/ [accessed 11 July 2014]

Bey-Bienko GY (1950) Fauna of the USSR. Insects. Blattodea. Trudy Zoologicheskogo Instituta Akademiya Nauk SSSR 40: 1-344.

Bey-Bienko GY (1957) Blattodea of Szechuan and Yunnan. Communication I. The results of the Chinese-Soviet zoologico-botanical expeditions to southwestern China 1955-1956. Entomologicheskoe Obozrenie 36(4): 895-915. 
Bey-Bienko GY (1969) New genera and species of cockroaches (Blattoptera) from tropical and subtropical Asia. Entomologicheskoe Obozrenie 48(4): 831-862.

Feng PZ, Woo FZ (1988) Three New Species and Two New Records of Blattaria From Yunnan and Guizhou, China. Entomotaxonomia 10(3-4): 305-312.

Guo YY, Feng PZ (1985) Descriptions of one new genus and two new species of Blattellidae (Blattodea). Entomotaxonomia 7(4): 333-336.

Hebard M (1929) Studies in Malayan Blattidae (Orthoptera). Proceedings of the Academy of Natural Sciences of Philadelphia 81: 1-109.

Liu XW, Zhu WB, Dai L, Wang HQ (2017) Cockroaches of southeastern China. Henan Science and Technology Press, Zhengzhou, 118-135.

Princis K (1969) Blattariae: Subordo Epilamproidea. Fam. Blattellidae. In: Beier M (Ed.) Orthopterprum Catalogus part 13: 713-1038.

Princis K (1971) Blattariae, Subordo Epilamproidea. Fam. Blattellidae. In: Beier M (Ed.) Orthopterprum Catalogus part 14: 1039-1224.

Roth LM (1977) A taxonomic revision of the Panesthiinae of the world I. The Panesthiinae of Australia (Dictyoptera: Blattaria: Blaberidae). Australian Journal of Zoology Supplementary Series 25(48): 1-122. https://doi.org/10.1071/AJZS048

Roth LM (1979) A taxonomic revision of the Panesthiinae of the world II. The genera Salganea Stål, Microdina Kirby, and Caeparia Stål (Dictyoptera: Blattaria: Blaberidae). Australian Journal of Zoology Supplementary Series 27(69): 1-201. https://doi.org/10.1071/ AJZS069

Roth LM (1984) The genus Symploce Hebard. I. Species from the West Indies. (Dictyoptera: Blattaria: Blattellidae). Entomologica Scandinavica 15(1): 25-63. https://doi. org/10.1163/187631284X00046

Roth LM (1985) A taxonomic revision of the genus Blattella Caudell (Dictyoptera, Blattaria: Blattellidae). Entomologica Scandinavica Supplement 22(1): 1-221.

Roth LM (1986) The genus Episymploce Bey-Bienko. I. Species chiefly from Java, Sumatra and Borneo (Kalimantan, Sabah, Sarawak). (Dictyoptera, Blattaria, Blattellidae). Entomologica Scandinavica 16(4): 355-374. https://doi.org/10.1163/187631285X00333

Roth LM (1987a) The genus Episymploce Bey-Bienko. III. Species from Laos, North and South Vietnam and Thailand. (Dictyoptera: Blattaria, Blattellidae). Entomologica Scandinavica 17(4): 455-474. https://doi.org/10.1163/187631286X00044

Roth LM (1987b) The genus Episymploce Bey-Bienko. IV. Species from India. (Dictyoptera: Blattaria, Blattellidae). Entomologica Scandinavica 18(2): 111-123. https://doi. org/10.1163/187631286X00378

Roth LM (1987c) The genus Episymploce Bey-Bienko. V. Species from China. (Dictyoptera: Blattaria, Blattellidae). Entomologica Scandinavica 18(2): 125-141. https://doi. org/10.1163/187631286X00378

Roth LM (1987d) The genus Episymploce Bey-Bienko. VI. Species from Taiwan and the Japanese Islands. (Dictyoptera: Blattaria, Blattellidae). Entomologica Scandinavica 18(2): 143153. https://doi.org/10.1163/187631286X00378

Roth LM (1991) New combinations, synonymies, redescriptions, and new species of cockroaches, mostly Indo-Australian Blattellidae. Invertebrate Taxonomy 5(5): 953-1021. https://doi.org/10.1071/IT9910953 
Roth LM (1995) The cockroach genera Hemithyrsocera Saussure, and Symplocodes Hebard (Dictyoptera: Blattellidae: Blattellinae). Invertebrate Taxonomy 9(5): 959-1003. https://doi. org/10.1071/IT9950959

Roth LM (1997) The cockroach genera Pseudothyrsocera Shelford, Haplosymploce Hanitsch, and Episymploce Bey-Bienko (Blattaria: Blattellidae, Blattellinae). Tijdschrift Voor Entomologie 140: 67-110.

Roth LM (2003) Systematics and Phylogeny of cockroaches (Dicty: Blattaria). Oriental Insects 37: 1-186. https://doi.org/10.1080/00305316.2003.10417344

Shiraki T (1908) Neue Blattiden und Forficuliden Japans. Trans. Sapporo. Nat. Hist. Soc., 2: 103-111.

Shiraki T (1931) Orthoptera of the Japanese Empire II. Blattidae. Insecta Mattsumrana 5(4): 171-209.

Wang ZQ, Song QZ, Feng PZ (2005) Blattodea: Blattidae, Blattellidae. In: Yang MF, Jin DC (Eds) Insects from Dashahe Nature Reserve of Guizhou. Guizhou People Press, Guiyang, Guizhou, 47-50.

Wang ZQ (2006) The Taxonomic study and Phylogeny of Blattellidae from China. PhD Dissertation, Beijing, Chinese Academy of Agricultural Sciences. 